\title{
Correction: Associations Between Digital Health Intervention Engagement, Physical Activity, and Sedentary Behavior: Systematic Review and Meta-analysis
}

Matthew Mclaughlin ${ }^{1,2,3,4}$, BSc; Tessa Delaney ${ }^{1,2,3,4}$, BND; Alix Hall ${ }^{1,2,3,4}$, PhD; Judith Byaruhanga ${ }^{1,2,3,4}$, MPH; Paul Mackie $^{5,6}$, MSc; Alice Grady ${ }^{1,2,3,4}$, PhD; Kathryn Reilly ${ }^{1,2,3,4}, \mathrm{PhD}$; Elizabeth Campbell ${ }^{1,2,3,4}$, PhD; Rachel Sutherland ${ }^{1,2,3,4}$, $\mathrm{PhD}$; John Wiggers ${ }^{1,2,3,4}$, PhD; Luke Wolfenden ${ }^{1,2,3,4}, \mathrm{PhD}$

\footnotetext{
${ }^{1}$ School of Medicine and Public Health, University of Newcastle, Callaghan, Australia

${ }^{2}$ Hunter New England Population Health, Wallsend, Australia

${ }^{3}$ Hunter Medical Research Institute, New Lambton Heights, Australia

${ }^{4}$ Priority Research Centre for Heath Behaviour, University of Newcastle, Callaghan, Australia

${ }^{5}$ School of Health Sciences and Priority Research Centre for Stroke and Brain Injury, University of Newcastle, Callaghan, Australia

${ }^{6}$ Centre for Research Excellence in Stroke Recovery and Rehabilitation, Florey Institute of Neuroscience, Melbourne, Australia
}

\section{Corresponding Author:}

Matthew Mclaughlin, BSc

School of Medicine and Public Health

University of Newcastle

University Drive

Callaghan, 2308

Australia

Phone: 610249246477

Email: Matthew.Mclaughlin1@ @ealth.nsw.gov.au

\section{Related Article:}

Correction of: https://www.jmir.org/2021/2/e23180/

(J Med Internet Res 2021;23(3):e29094) doi: 10.2196/29094

In "Associations Between Digital Health Intervention Engagement, Physical Activity, and Sedentary Behavior: Systematic Review and Meta-analysis" (J Med Internet Res 2021;23(2):e23180) a character display error was noted in 3 tables.

The "gamma" symbol $(\gamma)$ was not properly rendered in 5 places in the paper due to an XML conversion error.

In Table 4, row "Rebar et al," column "Association":

$$
=0.51(95 \% \text { CI }-1.77 \text { to } 2.72) ; P>.05
$$

has been corrected to:

$$
\gamma=0.51 \text { (95\% CI }-1.77 \text { to } 2.72 \text { ); } P>.05
$$

In Table 5, row "Rebar et al, Time," column "Association":

$$
=2.33 \text { (95\% CI } 0.09 \text { to } 4.64) ; P<.05
$$

has been corrected to:

$$
\gamma=2.33(95 \% \text { CI } 0.09 \text { to } 4.64) ; P<.05
$$

and:

$$
=0.51(95 \% C I-1.77 \text { to } 2.72) ; P>.05
$$

has been corrected to:

$$
\gamma=0.51(95 \% C I-1.77 \text { to } 2.72) ; P>.05
$$

In Table 5, row "Rebar et al, Logins," column "Association":

$$
=3.18 \text { (95\% CI } 1.15 \text { to 5.07); } P<.05
$$

has been corrected to:

$$
\gamma=3.18(95 \% \text { CI } 1.15 \text { to } 5.07) ; P<.05
$$
and:

$$
=2.04 \text { (95\% CI } 0.29 \text { to } 3.84) ; P<.05
$$

has been corrected to:

$$
\gamma=2.04 \text { (95\% CI } 0.29 \text { to } 3.84 \text { ); } P<.05
$$

The correction will appear in the online version of the paper on the JMIR Publications website on March 29, 2021, together with the publication of this correction notice. Because this was made after submission to PubMed, PubMed Central, and other full-text repositories, the corrected article has also been resubmitted to those repositories. 
This is a non-peer-reviewed article. Submitted 25.03.21; accepted 25.03.21; published 29.03.21.

Please cite as:

Mclaughlin M, Delaney T, Hall A, Byaruhanga J, Mackie P, Grady A, Reilly K, Campbell E, Sutherland R, Wiggers J, Wolfenden L Correction: Associations Between Digital Health Intervention Engagement, Physical Activity, and Sedentary Behavior: Systematic Review and Meta-analysis

J Med Internet Res 2021;23(3):e29094

URL: https://www.jmir.org/2021/3/e29094

doi: $10.2196 / 29094$

PMID: $\underline{33780346}$

CMatthew Mclaughlin, Tessa Delaney, Alix Hall, Judith Byaruhanga, Paul Mackie, Alice Grady, Kathryn Reilly, Elizabeth Campbell, Rachel Sutherland, John Wiggers, Luke Wolfenden. Originally published in the Journal of Medical Internet Research (http://www.jmir.org), 29.03.2021. This is an open-access article distributed under the terms of the Creative Commons Attribution License (https://creativecommons.org/licenses/by/4.0/), which permits unrestricted use, distribution, and reproduction in any medium, provided the original work, first published in the Journal of Medical Internet Research, is properly cited. The complete bibliographic information, a link to the original publication on http://www.jmir.org/, as well as this copyright and license information must be included. 